This is a preprint of an article whose final and definitive form has been published in Action

Learning: Research and Practice, July 2008, 5:2, 131 - 147 [copyright Taylor \& Francis]

Action Learning is available online at: http://journalsonline.tandf.co.uk/

The URL of this article is

http://www.informaworld.com/smpp/content $\sim \mathrm{db}=$ all? content $=10.1080 / 14767330802185673$

\title{
Cooperative Inquiry for Learning and Connectedness
}

\author{
Sonia Ospina \\ Waad El Hadidy \\ Amparo Hofmann-Pinilla
Research Center for Leadership in Action, Wagner Graduate School of Public Service, \\ New York University
}

April 2008

\section{ACKNOWLEDGEMENT}

This paper is based on experience from two programs supporting social change leadership: Leadership for a Changing World, funded by the Ford Foundation in partnership with the Advocacy Institute and Next Generation Leadership, funded by the Rockefeller Foundation. We would like to acknowledge the many contributions of the programs' coresearchers, and our partners at respective institutions, who over the course of the years have actively shaped our learning. We also wish to thank our colleague, Angie Chan, whose ideas greatly shaped this paper. 


\section{Introduction: cooperative inquiry for learning and connectedness}

Over the past few decades, academics and non-academics alike have raised concerns about higher education's self-serving patterns and deviation from a higher sense of purpose. Commentators have exposed reasons for why universities have become less than committed to their communities and society at large: increasing corporatization and commercialization of universities; declining research relevance in the face of complex real-life problems; and overwhelming attendance to labor market needs rather than needs of society as a whole are but a few examples (De Sousa Santos 1998; Kezar, Chambers, and Burkhardt 2005; O’Hara 2007; Shapiro 2005; Tight 1994). Other critics, including Bourdieu, Foucault and Derrida, have focused on the university and academics as perpetuators of social hierarchies through control over knowledge and entitled claims to the 'Truth' (Deer 2003).

Scholars have offered some solutions to university-society schism among which are service learning programs through which students undertake community projects as part of the curricula they are learning. Other responses have been more normative and holistic, calling upon universities to be more 'socially responsible' by operationalizing certain principles at the personal, social and university levels ${ }^{1}$. Yet another set of scholars have turned to action research and action learning approaches that implode the researcher-researched hierarchy and unite practice and theory in a way that privileges lived experience and relinquishes 'expert' control over knowledge (Reason 1999).

In this paper we focus on the potential role of cooperative inquiry (CI) to address this problem. CI is a systematic process of action and reflection among co-inquirers who are tackling a common question of burning interest (Bray et al. 2000; Kasal and Yorks 2002; Heron 1996; Charles and Glennie 2002; Ospina et al. 2007; Reason 1999; Yorks et al. 2007). Like other action-based approaches, CI aims to create change by improving professional practice, organizational outcomes or social democracy (Brooks and Watkins 1994). We argue that CI can help address the critical problem of the academic-practitioner divide because it offers opportunities for establishing a more meaningful relationship between these two groups, who are often considered worlds apart (Shani et al. 2007).

Cooperative inquiry, like action learning, represents an example of an action-based approach to inquiry and learning ${ }^{2}$ (Bray et al. 2000; Pedler and Burgoyne 2007). These can be viewed either as a methodology or as a general way of thinking reflected in methods emphasizing practice and action (Pedler and Burgoyne 2007). Combining the best of action learning and action research, CI affords equal value to learning and research in the service of action, giving primacy to practice as a source of knowing. Both CI and action learning emphasize the use of small working groups around participants' practice - what action learning practitioners call 'action learning sets' - with repeated cycles of action-reflection (Bray et al. 2000). Both share a core epistemic belief that theory and practice are not

\footnotetext{
${ }^{1}$ See Global University Network for Innovation: http:// www.guni-rmies.net/

2 Others are Action Research, Participatory Action Research, Action Science, and Appreciative Inquiry. Bray et al. (2000) call CI collaborative inquiry, but 'Cooperative' is the original term coined by pioneers like Heron (1996) and Reason (1999).
} 
separable and both critique detached forms of research and learning that flow from experts to practitioners. Other features specific to CI will become apparent in this paper ${ }^{3}$.

This paper reports on our efforts to integrate CI within a research agenda about leadership in social change organizations in the US. For seven years we have encouraged the formation of 13 CI groups of leaders who have inquired into self-formulated questions about their leadership around social change. We have done this within the academic context of a school of public affairs. As in other professional schools - such as management, social work and education - the academic-practitioner divide has important ramifications. Professional schools are founded precisely on the aspiration of connecting academics and professionals. Its members, unlike hard-science researchers in the laboratory, are committed to interacting with the inhabitants of the world they are trying to understand (Ospina and Dodge 2005a; Pettigrew 2001). Action-based approaches to learning and inquiry can be of great help to attain this aspiration, especially if they are given equal value to more traditional academic approaches.

We argue that capitalizing on CI for establishing connectedness is a not a simple application of CI in more research projects, nor a mere adherence to certain methodological requirements alone. The task is much more complex. This is so because at the heart of CI there are two logics - which we have labeled 'contestation' and 'transformation' - that must be confronted to be able to address the role of academia in deploying CI. Each logic stresses a particular demand. The logic of contestation upholds democracy, particularly the democratization of knowledge production, and may suggest that academics need to retreat from the CI arena. The logic of transformation upholds authority in the service of sociopolitical missions and could be interpreted as a call for academic institutions, especially those driven by values of justice, to claim their authority in using CI to fulfill larger social commitments.

Rather than polar demands, we conceive of democracy and authority as mediators and interlocutors in a dialectical relationship between academics and practitioners. Understanding the work as infused with dialectics means that both the research process and the roles of the parties involved are continually shaped, with each change representing growth towards enhanced connectedness. Grappling with CI as an inherently participatory approach allows the dialectics to flourish, creates the space for practitioners and academics to resolve tensions and presents multiple opportunities along the way that can be grasped for healing the divide in action.

\section{The practitioner-academic divide and the role of CI}

\section{The nature of the divide}

Notwithstanding the responsibility of universities to fulfill larger missions towards societies, the very nature of professional schools demands the production of knowledge that

\footnotetext{
3 The argument that CI can heal the practitioner-academic divide may apply equally to other action-oriented approaches including action learning. Since our experience is about cooperative inquiry, the insights are limited to this approach.
} 
is both informed by, and informs the world of, practice. Despite this imperative, professional schools have not been immune to the academe-practice disconnect. The specific manifestations of the disconnect have been well documented in the management field (Barley, Meyer, and Gash 1988; Bolton and Stolcis 2003; Feeney 2000; Huff 2000; Newland 2000; Reynolds and Vince 2004; Rynes, Bartunek, and Daft 2001).

The gap between academe and practice has been widened by a dominant mode of knowledge production that fixes researchers as 'producers' of knowledge and reduces the role of practitioners to 'subjects' of research and 'consumers' of knowledge, not as legitimate partners in the research process (Bradbury 2007; Gibbons et al. 1994; Rynes et al. 2001). In this mode, credentialed academics do research within the confines of their own disciplines and are only accountable to these communities (Gibbons et al. 1994: Werr and Greiner 2007). Tacit knowledge - personal, ephemeral and more difficult to formalize and most likely to resonate with practitioners - is dismissed in favor of explicit knowledge, which is codified into formal language to guide action (Dierkes et al. 2003; Gibbons 2000; Nonaka 1994). The results are disseminated via peer reviewed journals and conferences. Both applied and pure research are consumed at the end of, and outside of, the knowledge development process. Knowledge is then passed 'downstream' to practitioners who have been largely excluded from generating it, but are then expected to try to make it work in the real world.

Definitions of quality and value in academic research have also contributed to the gap. The academic system is self-referential. Relevance and quality criteria are internally created and controlled by scholarly peers. Success for research occurring within professional school contexts is closely linked to publication and citations in a limited number of highly reputed journals, seldom read by practitioners (Hodgkinson, Herriot, and Anderson 2001). Addressing the practical needs of practitioners does not yield scholarly reputation. In fact, extensive engagement with practitioners might threaten academic success (Werr and Greiner 2007).

Practitioners have also disserved connectedness by dismissing the contributions of serious theoretical thinking. Some practitioners become fixated on urgent matters and are not willing to partake in research that extends beyond their immediate needs. Repercussions of the gap include, at best, lost opportunities for practitioners to develop strategies and practices that draw upon vast knowledge and for academics to frame practically significant questions for research (Dodge et al. 2005; Ospina and Dodge 2005b; Shani et al. 2007; Weick 2001). At worst, the gap results in poor scholarship, where the normative recommendations of researchers and actual practices in applied settings do not coincide (Rynes, Bartunek, and Daft 2001).

\section{CI offers opportunities to heal the divide}

Embedded in CI are certain assumptions, democratic values and quality standards that make it particularly suitable for fostering connectedness between academics and practitioners. Like other participatory approaches, CI abandons the sharp distinction between researchers and objects of research by encouraging inquiry among co-researchers who participate fully in all stages. Anti-positivist but not anti-scientific, CI places the process of knowledge 
generation in the hands of ordinary practitioners and demystifies research by treating it as a form of learning (Brooks and Watkins 1994).

In the dominant mode discussed above, knowledge is passed down to practitioners. In contrast, CI validates practitioner experience forging a more direct link between intellectual knowledge and moment-to-moment personal and social action (Reason and Torbert 2001). Dominant research divorces action from theory, claiming that good theory guides action and is therefore, a priori, predictive and universal. Cooperative inquiry stresses the organic relationship between theory and action, seeing theory as derived in and from action (Reason 1998, 1999; Reason and Torbert 2001).

Practitioners of CI and other action learning approaches have rewritten the quality criteria that pervade traditional academic research, helping rethink what might be deemed valuable in inquiry. As a democratic approach, CI incorporates certain validity measures that encourage inquirers to systematically name and address power relations and to exercise critical subjectivity: the bracketing of pre-existing constructs and assumptions that may limit the exploration of new realms (Reason 1998). When incorporated by academics within their research endeavors, the democratic nature of CI then addresses concerns that universities perpetuate social inequalities through elitist production of knowledge (Heron and Reason 1997; Reason and Goodwin 1999).

\section{Underlying logics of CI and implications for healing the divide}

Realizing CI's potential to help heal the divide requires, first and foremost, a commitment to embrace two sets of fundamental assumptions of this method, each making up a logic that paradoxically suggests a different, almost reverse role for academia.

The logic of contestation

Implicit in the CI epistemology is a critique of the dominant knowledge production model. Reason (1999) argues that one purpose of CI is to '[relinquish] the monopoly of knowledge held traditionally by universities and other institutes of "higher learning" and [help] ordinary people regain the capacity to create their own knowledge in the service of their practical purposes' (207). One challenge, then, is to capitalize on CI for connectedness among academics and practitioners, while acknowledging that CI was conceived, in part, to counter academia's monopoly over 'valid' knowledge production (Brooks and Watkins 1994; Reason 1999).

Some may argue that when academics use CI they appropriate the method and reinforce their control over knowledge production. Albeit extreme, some commentators believe that any academic institutional involvement in CI wrongs the process (Zelman, in Bray et al. 2000, 140). Given such perspectives one resultant argument could be that academic institutions need to downplay their role in practitioner generated knowledge, in the spirit of democratizing knowledge generation.

Hence, there is a need to pay particular attention to democracy to maintain the integrity of the CI process. Democracy in this context implies a commitment to addressing and 
balancing power relations and giving up the privilege automatically conferred to academics as experts (Ospina et al. 2004). Paying attention to democracy is essential in its own right, but becomes even more critical when there are deep-seated power relations between universities and those traditionally deemed the 'objects' of research.

The logic of transformation

In contrast to the logic of contestation, some CI scholars call for academic institutions to step up their role in undertakings of social transformation. This logic converses on a paradigmatic and visionary level and we begin to see $\mathrm{CI}$ as embroiled in a political and moral endeavor. Reason (1998) argues that with its emphasis on developing participative action, CI can contribute to the emergence of 'communities of inquiry'. In a similar vein, Toulmin and Gustavsen (1996) write about the need to view research projects as 'political events', not just scientific happenings.

Within this wider mission CI scholars write about 'authoritative facilitation' and 'leadership'. For example, Reason states that the leaders of a society where democratic inquiry abounds must take their authority to propose and initiate collective action. They must in tandem invite others to reach towards a future state while creating democratic structures and relationships (Heron; 1999; Reason; 1998; Torbert; 1991). This wider socio-political call for action requires academics committed to a justice agenda. They must step in to lead and facilitate processes within their academic institutions.

As researchers, we share a social justice vision with the practitioners with whom we have collaborated. Our research agenda was premised on broader goals of changing the conversation about leadership in the US to call attention to values and practices espoused by social change organizations, such as inclusiveness and democracy. Because we perceive our work as contributing to a social vision, which entails learning and inquiry, we have claimed our authority in the service of that vision.

Embracing the two logics simultaneously

At first glance it may seem that these are contradictory logics espousing dichotomous aspirations; democracy being the crux of the matter for contenders of academic involvement in CI and authority being the claim for academics driven by justice and social transformation. The result, then, of explicitly choosing to hold the two logics in our practice, has been to keep a constant internal dialogue between our aspirations for democracy and authority. Doing so has meant engaging in a dialectical process with participants of CI groups, while claiming our authority in the service of a wider social goal while upholding democracy as pursuant to our own ideals and the ideals of CI. Context and positionality

How we handled the demands of democracy and authority was influenced - both facilitated and challenged - by three contextual factors: our institutional location and approach to understanding leadership; the programmatic context within which the CIs took place; and the practitioners who participated as co-researchers ${ }^{4}$.

\footnotetext{
${ }^{4}$ For a detailed description see Ospina et al. (2004, 2007).
} 
The research was embedded within a center in a professional school of public affairs in a large university. The center works with the premise that practitioners engage as learning partners to create together new knowledge that both contributes to leadership theory and translates into applicable and useful instruments for their work.

We study leadership with a relational lens (Uhl Bien and McKelvey 2007), focusing on shared meaning-making in the context of a group's work to accomplish a common purpose (Drath 2001; Drath and Palus 1994; Ospina and Sorensen 2006). This demands paying attention to the work of leadership as much as to the traits and behaviors of leaders. Consequently, practitioners join to inquire together about their experience of leadership. While CI is a particularly appropriate research methodology to employ in our work, other research methods have included participatory ethnography and narrative inquiry.

The CIs discussed in this article emerged in the context of research and development programs funded by prominent foundations intending to support social change leaders. Funds for the research and all related expenses were managed by the university. Broad research parameters were also set in advance of actual group formation. Participation was completely voluntary, although once a participant committed to a CI it was hoped they would engage all CI activities. Five to six action-reflection cycles were proposed over the course of eighteen months, with each meeting lasting about a day-and-a-half. There were four to eight inquirers and two external facilitators per group. Facilitator roles were defined by the group. Each group was asked to produce a report that synthesized the learning from the inquiry as an accountability mechanism to the broader program community. See Apendix 1 for a description of the CI questions and insights.

Participants in the groups were leaders of social change organizations recognized for their exceptional work. They worked in community-based organizations across the US, effectively addressing critical social problems in domains including community development, the arts, human rights, environmental justice, sexual and reproductive health, youth development and education. Their awareness of their own power and expertise to create change, values of social justice and suspicions towards university and large institutions made for some interesting dynamics in the planning and implementation of the CIs. Working them out in practice offered insights about the possibilities of reducing the divide.

\section{The dialectics of CI - contending with democracy and authority}

Our experience suggests that the logics of contestation and transformation, democracy and authority can co-exist and create synergies. Neither academics nor practitioners singlehandedly or pervasively influenced the CI encounter: both groups engaged in a dialectical relationship replete with fusions, fissures and negotiations that changed both the relationship and the inquiry. 
In highlighting these dialectics below, we attend to how democracy and authority were incarnated in the researchers' experience, accentuating our account with voices of participating inquirers. Our story of dialectics is told through three pertinent phases: (1) designing and initiating the CI groups; (2) addressing CI questions through the cycles; and (3) bringing the inquiries to closure and considering the outcomes.

The changes that resulted out of dialectical interaction within each of those phases represent moments of collaboration - materializations of a more meaningful relationship between academics and practitioners.

\section{Design and initiation}

In inviting program participants to form CIs, the researchers played the role of initiator. The literature on CI suggests that this process can be rather fickle and sensitive. Heron (1996) and Reason (1988) argue that initiators have a fine line to tread between generating member dependency, resistance, or alienation among group members if the initiators come on too strong, and creating confusion if they are too vague. Initiators face the challenge of creating a community of shared values without either imposing them or compromising them. This is the challenge of practicing democracy and authority hand-in-hand.

It was hard for the research team to act as initiators, notwithstanding our commitment to instill democratic relations. We uphold democracy from the outset by choosing cooperative inquiry (an inherently democratic action research approach) as an approach to develop the research agenda, rather than imposing a more traditional approach where participants would typically become 'objects' of research (Bradbury 2007). However, our first encounters with the program participants did not result in automatic endorsement for CI, enforcing the lesson that the mere choice of a participatory and democratic approach on its own is not enough to generate buy-in or to establish trust (Ospina et al. 2004).

Skepticism is reflected in the following statement from a participant: 'I have yet to understand the mysterious seductive power that CI holds over [the Center]: why this process to the exclusion of something else? Who controls the process holds the power.' (Paxton and Kasl 2006, 38) We argued that our responsibility for the research component of the broader program and our role in managing research funds demanded that we frame the constraints under which participants' choices could be made even before the participants had entered the programs. Yet, in designing the research we had selected CI as one of the 'containers' for doing research (Ospina et al. 2004) so that if the method was preset, the actual contents and concrete implementation could be decided by the practitioners with great flexibility. Some saw the logic, others remained skeptical.

Because the program incorporated new participants every year, the learning generated in early encounters led us to adapt the invitation process over time. We allowed ample time for participants to understand CI as a unique research method and to see the logic of the proposed procedure and timeline, offering participants more opportunities own their inquiries. We introduced ourselves not only as researchers, but as individuals with social justice interests and backgrounds. These were attempts to establish rapport before extending a formal invitation to form CI groups. We learned that the more participants viewed us as human beings rather than in the stereotypical researcher role, the more they were open to 
explore the invitation to engage in CI. As we built strong relationships with participants of previous CI groups, they became our recruitment allies for the new cohorts, giving testimony on what it was like to participate in a CI. Interested participants were asked to reflect on their own experiences of research so that CI could be discussed in light of those experiences. Only after the participants had gained a sense of the value of the process did we ask them to consider joining.

The selection of CI topics was also pregnant with dialectical tension. While participants were free to choose their own questions, the academic researchers provided a stipulation: the question must resonate with the goals of the leadership program. Part of our authority was vested in the program mandate to change the conversation about leadership in the US so that the work of social justice leaders would be more widely recognized. This behooved the generation of knowledge about leadership. Yet some participants were most interested in using research resources to produce technical information to advance the particular issues that drove their work. In upholding democracy, we opened room for practitioners to express their expectations and concerns, validating these and responding to them in the moment. Together, we brainstormed to find ways to use the research process to advance their work as much as possible, while still holding primary attention to insights into leadership practices. At times, we also used open space technology and other participatory approaches, to discuss potential questions that would propel participants' inquiries and motivate them to join. In the process, most participants discovered and appreciated the value of focusing attention on their leadership work. That the CI process 'allowed us to see our work both "up close" and "from a distance"' was the shared sentiment among one group (Almanza et al. 2004).

The dialectics that laced the initiation stage resulted in shifts for both the academics and the practitioners. They produced better understanding of one another and greater appreciation for what it means to collaborate. In the case of the academics, we had initially taken for granted the democracy inherent in CI as an approach, contrasted against other traditional research methods. The process taught us to accept distrust as a legitimate reaction from practitioners. We learned that enacting democracy is about deliberately establishing authentic relationships, rather than expecting democracy to reveal itself through the selection of a participatory research method.

Many participants entered the invitation stage with great suspicion. Those who decided to join CI groups took a risk, considering previous negative experiences with academics. Choosing to enter the relationship despite the apprehensions was a small step towards a more meaningful relationship. In the words of one participant: 'I took the plunge because I wanted to spend more time with the people in the group and learn from them' (Yorks et al. 2007, 24). This was a pragmatic motivation for a number of practitioners and one that helped alleviate the anxiety of entering into a researcher-supported process. Yet entering a relationship eventually transformed the practitioners' views of the academics and of the value of collaboration, as one participant indicated: 'I do see CI as different than the norm [within] universities. The CI isn't coming to dissect us. We were a part of a process, we were participating in it' (Research Center for Leadership in Action [RCLA] 2007, 16).

\section{Living the inquiry}


During the stage when the groups were living the inquiry, the dialectics took on a nested quality. They were emblematic of CI as a learning process and they also colored the relationship between the co-inquiring practitioners and the academic researchers. At multiple moments academics and practitioners shaped the process in a way that was more meaningful to each group.

After forming CIs, each group embarked on an iterative process of reflection and action geared towards answering their chosen questions about social change leadership. Since the interests of group members shaped each CI group, there was a lot of variation around the questions and on how the inquiries were developed. The list of questions Appendix 1 illustrates this variation.

Integral to the process of learning through $\mathrm{CI}$ is the idea that the process can never be prescribed or predicted (Reason 2006). Cooperative inquiry proponents use the analogy from complexity theory, edge of chaos. Cooperative inquiry is like a complex adaptive system which performs best when its order verges on its transition to chaos, heightening its dynamic patterns to robustness and responsiveness to context (Reason and Goodwin 1999). One co-inquirer used the metaphor of a hurricane to describe the process of emergence that she experienced within a CI: 'complex nonlinear interactions result in a dynamic field which is self-organizing, with the central axis of the hurricane acting as a peg for creative order to emerge.' (personal communication)

In several instances, we prodded the groups towards the central axis of the hurricane. For example, the academic team expected to bring closure to the groups by the fifth cycle as originally planned and encouraged group participants to articulate their learnings and findings in a neatly tied report. Yet sheer enthrallment in the CI, which is precisely the intention of the learning process, sometimes presented a challenge as the groups did not feel ready to move from the inchoate to the concrete. When one group negotiated for a sixth cycle the academic team resisted, yet in upholding democracy, acquiesced and thereon offered the opportunity of a sixth cycle to subsequent CI groups.

The dialectics mediated by democracy and authority were particularly poignant in the facilitators' roles. Facilitators offered particular skills and expertise about the CI process. They were also responsible for helping the group move towards synthesized findings to be documented in the report. Each group negotiated a more nuanced version of the facilitators' role autonomously. Some groups agreed that the facilitators would both bring the process expertise and participate as full co-inquirers. Others decided that the facilitators help the group members to move the process but would not take part of the inquiry.

Official facilitation in the CI groups raised a special conundrum for the facilitators, who both represented authority on behalf of the academic team and strived to enact the democracy inherent in the CI process. A facilitator of a CI group said: 'The tension I felt in terms of working in this context versus some other context was in-between a - for lack of a better term - sort of a food chain of money, which needed to be there, and having a sense of both collegial as well as other responsibilities to my colleagues at [the center], but also to the integrity of the process .... There really is this sort of dual role going on and it was letting it emerge.' (RCLA 2007, 5) 
In sum, the dialectics resulted in myriad nuances that shaped the emergence of each CI. As each CI was transpiring, spaces kept erupting for academics and practitioners to grapple with democracy and authority in shaping certain elements of the inquiring phase. Such grappling helped foster connectedness as both groups exercised their capacity to influence the movement towards the 'central axis of the hurricane', to shape the action-reflection cycles and to define and re-define the respective roles of the facilitators and the coinquirers.

Dialectical interaction also resulted in a more dramatic shift in the academic team's understanding of authority and democracy. Initially, the team claimed its authority in aligning the groups to the designated number of inquiry cycles, mainly out of a sense of responsibility for the funds provided. This understanding of authority shifted from being the enforcer of structure to being the catalyst for inquirers to truly participate and fully engage in upholding a vision for democratic inquiry. Walking the talk humanized researchers in the eyes of practitioners, who started to respect and trust them in ways they did not expect, given previous experiences with researchers. One participant said: ' ... There was a very strong emphasis on equity and a democratic process that was used that I think it really gave our group the chance, once we sort of relaxed into it, to become very close and spent a lot of time listening to the voices of everybody equally at the table.' (Ospina et al. 2007)

\section{Outcomes - what after the CI?}

When inquiries were coming to an end, numerous dialectical interactions resulted in shifts in roles and process that deemed the relationship more meaningful for both academics and practitioners. An unraveling discovery for participants ran parallel to the actual inquiry. Something to be learned about the process was equally, if not more, important than the answer to their questions. Group members were, in essence, learning about learning and were anxious to transcend the conical realm of their group and share knowledge with others. While the personal transformation was critical, participants wanted to capture the transformative elements for them. One CI member commented: 'I think these products, these pieces of paper, are very limited in that because they don't mean as much to other people reading them as they meant to you when you were doing it ... we put it down here and you say other people can learn from it, but it's really not how people learn, by reading that thing. It's not the same. It's not inspiring, like it is to do it.' (RCLA 2007, 14)

Many groups grappled with the idea of creating something over and above the required report to bring the experience and its meaning to a wider group of people. Initially the academic team had required a synthesis report from each group and planned to create publications themselves that further distilled the learning for a wider audience. When one group advocated for using a sixth meeting to do this, reshuffling budgetary allocations created resources to provide a professional editor. Prior to the group's request, the academic team had viewed coproduction as exclusively within the realm of the CI process. Coinquirers would produce knowledge from their own experience and then academics would create products for a broader audience. This interaction broadened the concept of coproduction and engaged practitioners in a function that was originally reserved for the academics, reshaping their typical roles while still drawing from their unique skills. 
In this interaction, democracy was enacted, but so too was authority. Many groups took ownership over their inquiries and the pursuant knowledge and wanted to similarly produce publications beyond the required synthesis report. However, the academic team had to claim its authority in several instances and decline suggestions for publications. As overseer of the research component, the team assessed the draft's pedagogical merit and potential to inspire change in others. The final product merited a publication beyond the automatic posting on the web only if it added something significantly novel to the existing understanding of practitioners outside the CI group. Ostensibly, by claiming authority in this way the academic team acted as gate-keeper of the knowledge. Here, enacting democracy by re-envisioning co-production did not imply the abdication of authority. Both democracy and authority were exercised hand-in-hand in a way that reconciled various interests and fostered a more collaborative relationship between practitioners and academics.

In the meantime, dialectical interaction also resulted in another shift in thinking. Embedded in larger projects that recognized and appreciated leadership, CIs became opportunities for leadership development since practitioners facing similar challenges came together in a democratic space that supported each other and allowed sharing knowledge. Through dialectical interaction, the practitioners once again pushed the academic team's thinking about leadership development, by desiring to extend CI to the practitioners' own communities. Several of the groups felt that CI was an emblem of democratic relations; of relations they wanted to cultivate within their communities and for an envisioned better world. One member in a group exploring issues of diversity commented that the unscripted flow of the inquiry was a motif of how people of color want to make positive change for the communities they are committed to: 'I have learned that developing a nurturing environment is a powerful tool to help disenfranchised communities learn how to navigate institutions.' (Paxton 2006, 63) The facilitator of that group mentioned: '[the group] was always conscious of the importance of taking their work and experience out into the world and loathed the idea of simply "navel-gazing."'(Paxton 2006, 13) The group made a pact, as a future endeavor, to articulate a tool that draws on the CI methodology and is more attuned to the needs and desires of people of color. Another group addressing financial sustainability also sought to transpose the CI method to a workshop methodology that stimulates peer-to-peer learning about fundraising strategies. The group created a multi-purpose publication that captured what they learned and also offered a tool that could be applied by others - of a fundraising workshop founded on the principles of CI (Holden et al. 2007).

That CI groups sought to transpose the methodology and the democratic relations it fosters to other contexts attests to the value derived from participating in a democratic inquiry. This is reflected in the words of one practitioner:

This CI gave me an unprecedented opportunity to move my work from a set of intuitions and assumptions into explicit, articulated, intentional practices. This was an essential growth for me, because it forced me to give up working in an enclosed universe of arts education peers, and to move into a wider universe of community arts organizers and social justice organizers working out of many diverse frameworks. We discovered together the language and practices that 
allow me to share my work and my thinking with a wider base of colleagues to model the values of inclusion and diversity that were part of my rhetoric but not fully part of my practice. (Yorks et al. 2007, 25)

The dialectical interactions that shaped both the outcomes and the value ascribed to them yielded a more fruitful relationship between academics and practitioners. The same practitioner added: 'I also deepened my taste for collaborating with academics - forging a praxis between theory and practice ...’ (Yorks et al. 2007, 25).

In summary, stories about the dialectics of the design, the inquiry and the outcomes suggest that academics and practitioners emerged differently from how they entered the relationship. Amidst these dynamics, democracy and authority acted as interlocutors rather than opposing forces. Democracy and authority were in-tandem aspirations, drivers and legitimators that greatly influenced each group's agenda and practice, as well as the nature of the relationship between academics and practitioners.

\section{Concluding remarks}

The university-society schism that is of much concern to both public leaders and intellectuals is reflected within the microcosm of university life by the well-documented gap that separates academic researchers and practitioners. The situation becomes even more problematic for graduate schools whose mission is to train professionals in practice areas of relevance to society. In such cases the mission of these academic programs demands bridging the academic-practitioner divide and reducing the gap between theory and practice. Action learning approaches have found receptivity within such professional schools, in part because their mandates require that explicit attention be paid to integrating professional practice and academic theorizing.

We have argued, based on our experience, that CI can play an important role in healing this divide. Embedded in the theory of $\mathrm{CI}$ are certain values, assumptions and validity criteria that help to alleviate some of the underlying causes of the gap. Additionally, its democratic underpinnings make CI more amenable to fostering connectedness between academics and practitioners. Cooperative inquiry stresses and encourages dialectical relationships among co-inquirers.

In designing, implementing and experiencing the success of thirteen CI groups with social change leaders we have understood our relationship as dialectical and constitutive. Academics and practitioners have both shaped the process and were shaped by the interaction. The stages of CI groups were replete with collaborative moments. Each resultant nuance, shift or modification represented a step towards enhanced connectedness. The divide was thus being healed in the action - in working through issues collaboratively rather than as some victorious end result independent of the work. Moments of intense interaction - whether in the form of tensions or authentic encounters - comprised the actual work of healing the divide. They were not interruptions or deviations from the process. Amidst these dialectical interactions, authority and democracy appeared as interlocutors, rather than contradictory demands. In our experience, being democratic did not mean 
abdicating our authority and claiming our authority did not mean that we were compromising on democracy. One important lesson for academics harnessing CI for connectedness is to be cognizant of the interplay between democracy and authority, think about what drives it and name it as it intersects the relationship.

Another lesson is to mirror the dialectics embedded in the CI learning process in the academic relationship with practitioners. By engaging in the dialectics, in our case, the goals of practitioners and academics were validated and supported and genuine collaboration based on strong trusting relationships - was fostered. Our experience suggests that CI can play an important role in helping to reduce the practitioner-academic divide, contributing to bringing the university back into society. The practitioners we worked with recognized this feat and encouraged us to claim our authority in its pursuit. One of them saw this as a moral imperative:

Maybe you [academics] have a vision about what ... the university can do in our huge society that's different from what it's been doing. If that's true, we [practitioners] want you to go and do that. We want you to be a university that has reached down to the grassroots and [has] taken some time ... and got some money ... and looked at the intelligence and incredible resources and incredible power that's there, and [will] hold it up to the world in a different way. But you have to do that. (RCLA 2007, 17)

Introducing CI and other action-based approaches to professional schools offers a great opportunity to continue to heal the divide. The CI process motivates academics and practitioners to negotiate the dialectics of authority and democracy, while creating connectedness and understanding. Both groups are thus able to view the other differently and to appreciate the value of their collaboration. 


\section{Notes on contributors}

Sonia Ospina is an associate professor of Public Management and Policy and faculty director of the Research Center for Leadership in Action at New York University's Wagner Graduate School of Public Service. Her areas of interest are social change leadership, accountability and democratic governance, qualitative research and action research.

Waad El Hadidy is a research associate at the Research Center for Leadership in Action at New York University’s Wagner Graduate School of Public Service. Her research interests lie at the intersection of international development and social justice discourse and practice.

Amparo Hofmann-Pinilla is the deputy director and a researcher for the Research Center for Leadership in Action at New York University’s Wagner Graduate School of Public Service. She directs the international and social change leadership strategic initiatives. Her areas of interest are social movements, popular education, social change leadership, culture/identity and action research. 


\section{References}

Almanza, S., M. Byrne-Jimenez, M. de la Uz, S. Eilart, T. Holden, M. Houghton, L. Smith, and O. Warren. 2004. Successful social change leading and its values: Discovery through cooperative inquiry. New York: Research Center for Leadership in Action, NYUWagner.

Barley, S.R., G.M. Meyer, and D.C. Gash. 1988. Cultures of culture: Academics, practitioners and the pragmatics of normative control. Administrative Science Quarterly 33, no. 1: 24-60.

Bolton, M.J., and G.B. Stolcis. 2003. Ties that do not bind: Musings on the specious relevance of academic research. Public Administration Review 63, no. 5: 626-30.

Bradbury, H. 2007. Quality and 'actionability’: What action researchers offer from the tradition of pragmatism. In Handbook of collaborative management research, ed. A. B. Shani, S. A. Mohram,

W. A. Pasmore, N. Adler, and B. Styme. London: Sage. Bray, J., J. Lee, L. Smith, and L. Yorks. 2000. Collaborative inquiry in practice: Action, reflection, and meaning making. Thousand Oaks, CA: Sage.

Brooks, A., and K.E Watkins. 1994. A new era for action technologies: A look at the issues. In The emerging power of action inquiry technologies: New directions for adult and continuing education, ed. A. Brooks and K.E. Watkins. San Francisco, CA: Jossey-Bass.

Charles, M., and S. Glennie. 2002. Co-operative inquiry: Changing inter-professional practice. Systemic Practice and Action Research, 15(Special issue), The Practice of Cooperative Inquiry, no. 3: 38-55.

Deer, C. 2003. Bourdieu on higher education: The meaning of the growing integration of educational systems and self-reflective practice. British Journal of Sociology of Education 24, no. 2: 195-207.

De Sousa Santos, B. 1998. de La Mano de Alicia-Lo Social y Lo Politico. Bogota, Columbia: Siglo del Hombre Editores.

Dierkes, M., A.B. Antal, J. Child, and I. Nonaka. 2003. Handbook of organizational learning and knowledge. Oxford: Oxford University Press.

Dodge, J., M. Ospina, and E.G. Foldy. 2005. Integrating rigor and relevance in public administration scholarship: The contribution of narrative inquiry. Public Administration Review 65, no. 3: 286-300.

Drath, W.H. 2001. The deep blue sea: Rethinking the source of leadership. San Francisco, CA: Jossey-Bass. 
Drath, W.H., and J.P. Palus. 1994. Making common sense: Leadership as meaning-making in a community of practice. Greensboro, NC: Center for Creative Leadership.

Feeney, S. 2000. Symposium: Authority, legitimacy, voice and the scholar-practice question. Nonprofit and Voluntary Sector Quarterly 29, no. 1: 5-10.

Gibbons, M. 2000. Mode 2 society and the emergence of context-sensitive science. Science and Public Policy 27, no. 3: 159-63.

Gibbons, M., C. Limoges, H. Nowotny, S. Schwartzman, P. Scott, and M. Trow. 1994. The new production of knowledge: The dynamics of science and research in contemporary societies. London: Sage.

Heron, J. 1996. Overview of co-operative inquiry. In Co-operative inquiry: Research into the human condition. ed. H. Heron. London: Sage. 1999. The complete facilitator's guide. London: Sage.

Heron, J., and P. Reason. 1997. A participatory inquiry paradigm. Qualitative Inquiry 3: 274-94.

Hodgkinson, G.P., P. Herriot, and N. Anderson. 2001. Re-aligning the stakeholders in management research: Lessons from industrial, work and organizational psychology. British Journal of Management 12 (Special issue): S41-S48.

Holden, T., J. Arvizu, S. Bring, M. Johnson, A. Kim, K. Lind, S. Ospina, and B. Shelby. 2007. Better together: Peer-led fundraising workshops for change. New York: Research Center for Leadership in Action, NYUWagner.

Huff, A.S. 2000. Changes in organizational knowledge production. Academy of Management Review 25, no. 2: 288-93.

Kasl, E., and L. Yorks. 2002. An extended epistemology for transformative learning theory and its application through collaborative inquiry. University of Columbia: Teachers College Record.

Kezar, A.J., T.C. Chambers, and J.C. Burkhardt. 2005. Higher education for the public good: Emerging voices from a national movement. San Fransisco, CA: Jossey-Bass.

Newland, C.A. 2000. The public administration review and ongoing struggles for connectedness. Public Administration Review 57, no. 5: 20-38.

Nonaka, I. 1994. A dynamic theory of organizational knowledge creation. Organizational Science 5, no. 1: 14-37. 
O’Hara, M. 2007. Strangers in a strange land: Knowing, learning and education for the global knowledge society. Futures 8: 930-41.

Ospina, S., J. Dodge, B. Godsoe, J. Minieri, S. Reza, and E. Schall. 2004. From consent to mutual inquiry: Balancing democracy and authority in action research. Action Research 2, no. 1: 47-69.

Ospina, S., and J. Dodge. 2005a. It's about time: Catching method up to meaning-the usefulness of narrative inquiry in public administration research. Public Administration Review 65, no. 2: 143-57.

—. 2005b. Narrative inquiry and the search for connectedness: Practitioners and academics developing public administration scholarship. Public Administration Review 65, no. 4: 409-23.

Ospina, S., J. Dodge, E.G. Foldy, and A. Hofmann-Pinilla. 2007. Taking the action turn: Bringing participation and qualitative research in reason. In Handbook of action research, participative inquiry and practice (2nd edition), ed. P. Reason and H. Bradbury, 420-34. London: Sage.

Ospina, S., and G. Sorenson. 2006. A constructionist lens on leadership: Charting new territory. In The quest for a general theory of leadership, ed. G. Goethals and G. Sorenson, 188-205. Cheltenham: Edward Elgar.

Paxton, D. with cooperative inquiry participants. 2006. Navigating power and sustaining leadership: People of color creating change to support children, youth, and families. Working document. New York: Research Center for Leadership in Action, NYUWagner.

Pedler, M., and J.G. Burgoyne. 2007. From PRA to PLA and pluralism action learning. In The Sage handbook of action research, ed. P. Reason and H. Bradbury. London: Sage.

Paxton, D., and E. Kasl. with cooperative inquiry participants. 2006. Art, creative practice, action and leadership. Working document. New York: Research Center for Leadership in Action, NYUWagner.

Pettigrew, A.M. 2001. Management research after modernism. British Journal of Management 12 (Special issue): S61-S70.

Research Center for Leadership in Action. 2007. Leadership for a changing world conversation on cooperative inquiry. Working report on symposium held on 8 December, 2006, NYUWagner.

Reason, P. 2006. Choice and quality in action research practice. Journal of Management Inquiry 15, no. 2: 187-203, (Developed from Keynote Address, World Congress of Participatory Action Research, Pretoria, South Africa, September 2003). 
- 1998. Political, epistemological, ecological and spiritual dimensions of participation studies in cultures. Organizations and Societies 4: 147-67.

- 1999. Integrating action and reflection through co-operative inquiry. Management learning 30, no. 2: 207-27.

Reason, P., and B. Goodwin. 1999. Toward a science of qualities in organizations: Lessons from complexity theory and post-modern biology. Concepts and Transformations 4, no. 3: 281-17.

Reason, P., and B. Torbert. 2001. The action turn: Toward a transformational social science. Concepts and Transformations 6, no. 1: 1-37.

Reynolds, M., and R. Vince. 2004. Critical management education and action-based learning: Synergies and contradictions. Academy of Management Learning and Education 3, no. 4: 442-56.

Rynes, S.L., J.M. Bartunek, and R.L. Daft. 2001. Across the great divide: Knowledge creation and transfer between practitioners and academics. Academy of Management Journal 44, no. 2: 340-75.

Shani, A.B, S.A. Mohrman, W.A. Pasmore, B. Stymne, and N. Adler. 2007. The promise of collaborative management research. Handbook of collaborative management research, eds. A.B. Shani, S.A. Mohrman, W.A. Pasmore, B. Stymne and N. Adler, 7-32. Thousand Oaks, CA: Sage.

Shapiro, H.T. 2005. A larger sense of purpose: Higher education and society. Princeton, NJ: Princeton University Press.

Tight, M. 1994. Crisis, what crisis? Rhetoric and reality in higher education. British Journal of Educational Studies 42, no. 4: 333-74.

Torbert, W.R. 1991. The power of balance: Transforming self, society, and scientific inquiry. Newbury Park, CA: Sage.

Toulmin, S., and B. Gustavsen. 1996. Beyond theory: Changing organizations through participation. Amsterdam: John Benjamins.

Uhl Bien, M.R., and B. McKelvey. 2007. Complexity leadership theory: Shifting leadership from the industrial age to the knowledge era. Leadership Quarterly 18, no. 4: 298-318.

Weick, K.E. 2001. Gapping the relevance bridge: Fashions meet fundamental in management research. British Journal of Management 12 (Special issue): S71-S75. 
Werr, A., and L. Greiner. 2007. Collaboration and the production of management knowledge in research, consulting, and management practice. In Handbook of collaborative management research, eds.

A.B. Shami, S.A. Mohram, W.A. Pasmore, B. Stymne and N. Adler, 93-118. Thousand Oaks, CA: Sage.

Yorks, L., A. Aprill, L. James, A. Ress, S. Ospina, and A. Hofmann-Pinilla. 2007. The tapestry of leadership: Lessons from six cooperative inquiry groups of social justice leaders. In Handbook of action research, participative inquiry and practice (2nd edition) ed. P. Reason and H. Bradbury, 487-96. London: Sage. 


\section{Appendix 1. Cooperative inquiry groups}

\begin{tabular}{|c|c|c|}
\hline Group/Members & CI Question & Summary \\
\hline $\begin{array}{l}\text { A Dance That Creates } \\
\text { Equals: "Unpacking" } \\
\text { Leadership Development }\end{array}$ & \multirow{2}{*}{$\begin{array}{l}\text { How can we create the } \\
\text { space and opportunities for } \\
\text { individuals to recognize } \\
\text { themselves as leaders and } \\
\text { develop leadership? }\end{array}$} & \multirow{2}{*}{$\begin{array}{l}\text { Group viewed leadership development as a shift in } \\
\text { the leadership relationship with some stepping up and } \\
\text { others stepping back. Not about granting power but } \\
\text { recognizing innate power. Group offered set of tools } \\
\text { for leadership development }\end{array}$} \\
\hline $\begin{array}{l}\text { Denise Altvater; Bethany } \\
\text { Godsoe (Facilitator); LaDon } \\
\text { James; Barbara Miller; } \\
\text { Sonia Ospina (Facilitator); } \\
\text { Tyletha Samuels; Cassandra } \\
\text { Shaylor; Lateefah Simon; } \\
\text { Mark Valdez }\end{array}$ & & \\
\hline $\begin{array}{l}\text { Social Justice Leadership } \\
\text { and Movement Building: } \\
\text { The Council }\end{array}$ & \multirow{2}{*}{$\begin{array}{l}\text { How do we, as grassroots } \\
\text { community organizers, } \\
\text { keep our organizational } \\
\text { autonomy and build a } \\
\text { wider movement to bring } \\
\text { justice to our } \\
\text { communities? }\end{array}$} & \multirow{2}{*}{$\begin{array}{l}\text { Members participated in political actions in each } \\
\text { other's communities with the common vision of } \\
\text { health and life for all people. Embracing this common } \\
\text { vision means developing "unity of will" rather than } \\
\text { "unity of organization", and strengthening a } \\
\text { movement rather than creating one. They viewed } \\
\text { leadership as a cyclic process developed collectively } \\
\text { among a group of people that includes learning, } \\
\text { planning, and action. }\end{array}$} \\
\hline $\begin{array}{l}\text { Dale Asis; Rufino } \\
\text { Dominguez; Janet Fout; } \\
\text { Sylvia Herrera; Sarah } \\
\text { James; Lewis Jordan } \\
\text { (Facilitator); Wing Lam; D. } \\
\text { Milo Mumgaard; Salvador } \\
\text { Reza; Linda Sartor; Gustavo } \\
\text { Torres; Ruth Wise Group }\end{array}$ & & \\
\hline $\begin{array}{l}\text { Don't Just Do Something, } \\
\text { Sit There }\end{array}$ & \multirow{2}{*}{$\begin{array}{l}\text { How can we be more } \\
\text { effective in helping others } \\
\text { become more strategic, } \\
\text { conceptual, and creative in } \\
\text { their thinking? }\end{array}$} & \multirow{2}{*}{$\begin{array}{l}\text { This group began with the realization that as } \\
\text { organizers they could teach organizing, but were not } \\
\text { good at getting people to think strategically. They } \\
\text { realized that in order to do so they we would have to } \\
\text { be more intentional about being more strategic, } \\
\text { creative, and conceptual in their relationship with } \\
\text { learners. }\end{array}$} \\
\hline $\begin{array}{l}\text { Victoria Kovari;Reverend } \\
\text { Tyrone Hicks; Larry } \\
\text { Ferlazzo; Craig McGarvey; } \\
\text { Mary Ochs; Lucia Alcántara } \\
\text { (Facilitator); Lyle Yorks } \\
\text { (Facilitator) }\end{array}$ & & \\
\hline $\begin{array}{l}\text { Successful Social Change } \\
\text { Leading and Its Values }\end{array}$ & \multirow{2}{*}{$\begin{array}{l}\text { What makes social change } \\
\text { leadership successful and } \\
\text { what values are held in } \\
\text { common across such } \\
\text { diverse leaders and } \\
\text { organizations? }\end{array}$} & \multirow{2}{*}{$\begin{array}{l}\text { Members interviewed other social change leaders } \\
\text { from the community. A major outcome was } \\
\text { expanding members' understanding of the role of } \\
\text { relationship and its application to reflective activities } \\
\text { and more visible leadership communication actions. } \\
\text { The group identified certain values that operate in } \\
\text { social change leadership. They also defined a multi- } \\
\text { leveled dynamic named "we-ness" which focuses on } \\
\text { pursuing the collective good }\end{array}$} \\
\hline $\begin{array}{l}\text { Susana Almanza; Mónica } \\
\text { Byrne-Jiménez (Facilitator); } \\
\text { Michelle de la Uz; Stan } \\
\text { Eilert; Theresa Holden; } \\
\text { Mary Houghton; Linda } \\
\text { Smith (Facilitator); Deborah } \\
\text { Warren }\end{array}$ & & \\
\hline
\end{tabular}




\begin{tabular}{|c|c|c|}
\hline $\begin{array}{l}\text { Can the Arts Change the } \\
\text { World? }\end{array}$ & \multirow{2}{*}{$\begin{array}{l}\text { How and when does art } \\
\text { release, create, and } \\
\text { transform power for social } \\
\text { change? }\end{array}$} & \multirow{2}{*}{$\begin{array}{l}\text { This group learned that the arts are a transformative } \\
\text { tool for communities, by creating a safe space for } \\
\text { trust and reflection, by creating something new, for } \\
\text { dealing with harsh realities, by honoring the past, and } \\
\text { making role shifting comfortable. }\end{array}$} \\
\hline $\begin{array}{l}\text { Arnold Aprill; Kathryn } \\
\text { Cutler (Translator); Sandra } \\
\text { Hayes (Facilitator); Elise } \\
\text { Holliday; Fahari Jeffers; } \\
\text { Nobuku Miyamoto; Pamela } \\
\text { Parham (Translator); Abby } \\
\text { Scher; Diana Spatz; Richard } \\
\text { Townsell; Lily Yeh; Lyle } \\
\text { Yorks (Facilitator) }\end{array}$ & & \\
\hline $\begin{array}{l}\text { Sustaining A Powerful } \\
\text { Social Justice Movement }\end{array}$ & \multirow{2}{*}{$\begin{array}{l}\text { How do we engage and } \\
\text { sustain a social justice } \\
\text { movement that seizes } \\
\text { power? }\end{array}$} & \multirow{2}{*}{$\begin{array}{l}\text { This group found that movement, much like truth, can } \\
\text { be subjective. Therefore, they strongly advocate for } \\
\text { the creation of conditions that support the self- } \\
\text { determination of constituents within the organizing } \\
\text { group, community, and society as a whole. }\end{array}$} \\
\hline $\begin{array}{l}\text { Lucia Alcántara } \\
\text { (Facilitator); Kehaulani } \\
\text { Filimoe’atu; Wanda } \\
\text { Hopkins; Rose Miller } \\
\text { (Facilitator); Anita Rees; } \\
\text { Ken Tool; Marcy } \\
\text { Westerling }\end{array}$ & & \\
\hline $\begin{array}{l}\text { Integrating Human } \\
\text { Rights, Social Justice, \& } \\
\text { Sustainability }\end{array}$ & \multirow{2}{*}{$\begin{array}{l}\text { How can we build a } \\
\text { movement which } \\
\text { integrates human rights, } \\
\text { social justice, and } \\
\text { ecological sustainability? }\end{array}$} & \multirow{2}{*}{$\begin{array}{l}\text { The "vision" must be far-reaching and grounded in } \\
\text { the here and now, both global in its ecological and } \\
\text { social-political tenets and local in its potential for } \\
\text { implementation. Social change leaders likely need a } \\
\text { "strategic plan" to help prioritize diverse goals within } \\
\text { the broader vision, to integrate diverse elements in } \\
\text { ways that are radical and synergistic, rather than } \\
\text { based primarily on compromise, and to enable people } \\
\text { to actively shape the vision, while changing } \\
\text { themselves. }\end{array}$} \\
\hline $\begin{array}{l}\text { Diana Bustamante; Anthony } \\
\text { Flaccavento; Sandra Hayes } \\
\text { (Facilitator); Sarah Ludwig; } \\
\text { Juan E. Rosario; Mily } \\
\text { Treviño-Sauceda; Isabel } \\
\text { Toscano; Imani Walker; } \\
\text { Lisa Diane White; Lyle } \\
\text { Yorks (Facilitator) }\end{array}$ & & \\
\hline $\begin{array}{l}\text { Developing Sustainable } \\
\text { Social Change } \\
\text { Organizations }\end{array}$ & \multirow[t]{2}{*}{$\begin{array}{l}\text { How do we raise money to } \\
\text { develop sustainable social } \\
\text { change organizations? }\end{array}$} & \multirow{2}{*}{$\begin{array}{l}\text { This group identified common issues in raising } \\
\text { money for social change organizations and discovered } \\
\text { the value of peer support for people responsible for } \\
\text { fundraising in their organizations. Group members } \\
\text { are constructing a model for a series of peer-led } \\
\text { fundraising workshops for social change organization } \\
\text { leaders. }\end{array}$} \\
\hline $\begin{array}{l}\text { John Arvizu; Suzanne } \\
\text { Bring; Theresa Holden } \\
\text { (Facilitator); Michele } \\
\text { Nicole Johnson; Alice Kim; } \\
\text { Kevin Lind; Sonia Ospina } \\
\text { (Facilitator); Beatrice } \\
\text { Shelby }\end{array}$ & & \\
\hline
\end{tabular}




\begin{tabular}{|c|c|c|}
\hline $\begin{array}{l}\text { Art, Creative Practice, } \\
\text { Action and Leadership }\end{array}$ & \multirow{2}{*}{$\begin{array}{l}\text { How can I claim my own } \\
\text { power as an artist/cultural } \\
\text { worker, and in that help } \\
\text { create more vital and } \\
\text { respected space for artists and } \\
\text { cultural workers in society in } \\
\text { general, and in the work for } \\
\text { social change in specific? }\end{array}$} & \multirow[t]{2}{*}{$\begin{array}{l}\text { The group unearthed themes they considered to } \\
\text { 'stretch across the arc of the entire'. These include } \\
\text { Ritual, place, healing, culture, and heart. }\end{array}$} \\
\hline $\begin{array}{l}\text { Elizabeth Canner; Kathie } \\
\text { deNobriga; Timothea } \\
\text { Howard; Elizabeth Kasl } \\
\text { (Facilitator); Annie } \\
\text { Lanzillotto; Pam } \\
\text { McMichael; Cara Page; } \\
\text { Doug Paxton (Facilitator) }\end{array}$ & & \\
\hline $\begin{array}{l}\text { Navigating Power and } \\
\text { Sustaining Leadership: } \\
\text { People of Color Creating } \\
\text { Change to Support } \\
\text { Children, Youth and } \\
\text { Families }\end{array}$ & \multirow[t]{2}{*}{$\begin{array}{l}\text { How do we do our work } \\
\text { while we navigate the power } \\
\text { structures, join with others } \\
\text { and nourish our minds, hearts } \\
\text { and bodies along the way? }\end{array}$} & \multirow{2}{*}{$\begin{array}{l}\text { Five categories of findings seemed be present all } \\
\text { along the journey: the challenge and complexity of } \\
\text { race \& culture, healing, regeneration and self-care, } \\
\text { navigating the dance of power, elements of } \\
\text { sustaining leadership, and building community } \\
\text { through soul work. When the group gathered for } \\
\text { its final meeting, they did not just look back at } \\
\text { outcomes, but also forward to outcomes for the } \\
\text { future in terms of how to share their CI experience } \\
\text { with communities of color. }\end{array}$} \\
\hline $\begin{array}{l}\text { Jay Alire; Hilaria Bauer; } \\
\text { Raj Jayadev; Emily Lopez; } \\
\text { Sonya Lopez; Carlos } \\
\text { Pineda; Doug Paxton } \\
\text { (Facilitator); Marian } \\
\text { Urquilla }\end{array}$ & & \\
\hline Got Privilege? & \multirow{2}{*}{$\begin{array}{l}\text { How can we create conditions } \\
\text { that help a group of people } \\
\text { who are diverse in culture and } \\
\text { race to have an honest } \\
\text { conversation about systemic } \\
\text { privilege? }\end{array}$} & \multirow{2}{*}{$\begin{array}{l}\text { The group initially aimed to integrate the NGL } \\
\text { fellowship experience into their life and work. The } \\
\text { journey evolved into an exploration of privilege } \\
\text { and race. The group closed with questions about } \\
\text { creating the conditions for a mixed race group to } \\
\text { have an authentic conversation about systemic } \\
\text { racism, creating even ground for personal risk. }\end{array}$} \\
\hline $\begin{array}{l}\text { JoAnn Chase; Cynthia } \\
\text { Choi; Mark Winston } \\
\text { Griffith; Lisa Hasegawa; } \\
\text { Jacqueline Kaplan; } \\
\text { Elizabeth Kasl (Facilitator); } \\
\text { Annie Lanzillotto; Gepsie } \\
\text { Metellus; Hilary Morgan } \\
\end{array}$ & & \\
\hline
\end{tabular}

